\title{
EL DESARROLLO MORAL COMO DESARROLLO \\ HUMANO INTEGRO. ANÁLISIS ÉTICO \\ Y PSICOPEDAGÓGICO
}

\author{
Pedro Luis BLASCO AZNAR \\ Departamento de Filosofía \\ Universidad de Zaragoza
}

RESUMEN: La psicología moral, la pedagogía moral, etc. asumen, generalmente de forma implícita y poco crítica, alguno de los sistemas morales vigentes; así lo ponen de manifiesto las teorías aquí expuestas. Ahora bien, no habría moral alguna si la naturaleza humana no fuera naturaleza moral, como también es naturaleza racional, etc. Lo cual exige pensar una filosofía moral desde su ineludible fundamento antropológico, es decir, centrada en el hombre, en su unidad y totalidad, así como pensar una concepción humana de la moral, no una concepción ética o autorreferencial de la moral. Consecuente con esta moral antropológica, expongo sus implicaciones para un planteamiento psicopedagógico del desarrollo moral como desarrollo humano íntegro.

DESCRIPTORES: Filosofía moral, psicología moral, pedagogía moral, desarrollo moral.

ABSTRACT: Moral psychology, moral pedagogy, etc. usually adopt some of current moral systems in an implicit and uncritical form. Or this is, at least, what the theories here analysed state. Now then, morals wouldn't exist if human nature were not moral nature just as it is rational nature, etc. which demands to think a moral philosophy from its unavoidable anthropological foundation, that is a moral philosophy centred on man, on his unity and totality, as well as to think a human conception of morals, not an ethical or auto-referential conception of morals. Consistently with these 
anthropological morals, I show its implications in a psychopedagogic approach to the moral development as a complete human development.

KEYWORDS: moral philosophy, moral psychology, moral pedagogy, moral development.

\section{Introducción}

No habría moral y, por lo tanto, tampoco normas, valores, problemas morales, ni psicología moral o pedagogía moral, etc. si el hombre no fuera en sí mismo constitutivamente moral; más aún, la inmensa pluralidad de sistemas y de teorías morales que regulan la conducta humana en toda época y lugar pone bien de manifiesto la universalidad del hecho moral; universalidad que sería imposible e impensable si en ella no se pusiera en evidencia la naturaleza moral del hombre: esta misma universalidad testifica que el hombre es constitutivamente mora y es su consecuencia; es decir, es manifestación de la moralidad intrínseca a la naturaleza humana o del hecho de que la naturaleza humana es constitutivamente moral.

Pero frecuentemente ha carecido el pensamiento de una reflexión orientada a dilucidar tanto este hecho universal de la moral como las mismas teorías y problemas morales, y sobre todo la misma naturaleza moral del hombre, que es la raíz de tales teorías y problemas; a comprender, en definitiva, el sentido o significado originario y más profundamente humano de la moral. Ciertamente, para eso está la filosofía; por lo tanto, las investigaciones sobre la moral desde otras áreas del pensamiento como la psicología, la pedagogía, la sociología o la religión se han limitado generalmente en este punto a constatar como fenómeno puramente fáctico el hecho concreto de las distintas morales conocidas y sobre todo vigentes en una época, asumiendo desde su propia perspectiva y teoría psicológica, pedagógica, sociológica, o religiosa, una u otra de esas teorías morales, muchas veces de forma implícita. Pero la asumen de manera un tanto dogmática, sin la crítica necesaria y previa de esa amplia oferta filosófica y fáctica de sistemas morales. Toda psicología moral, así como toda pedagogía moral, además de otros supuestos específicamente psicológicos y pedagógicos, tiene como fundamento o punto de referencia una concepción ética o filosófico-moral, generalmente más implícita que temáticamente pensada. De manera que algunas diferencias entre estas teorías 
morales psicológicas y pedagógicas tienen su origen en sus respectivos fundamentos filosóficos y morales tan distintos como las éticas de inspiración kantiana, neoaristotélica o utilitarista, por ejemplo, que han asumido.

Recordaré aquí, en primer lugar, alguna alusión puntual a determinadas y bien conocidas teorías de la psicología y educación morales en crítica con las cuales se pondrá bien de manifiesto el sentido del tema de este estudio porque se trata, en segundo lugar, de plantear y de explicar en sus rasgos más definitorios el desarrollo moral de las personas en su integridad, el desarrollo moral de cada persona como desarrollo humano y como desarrollo íntegro del ser humano. Lo cual significa elaborar una particular filosofía moral concebida necesariamente, a mi modo de ver, desde su ineludible fundamento antropológico en el sentido que expondré más adelante; filosofía moral que entiende el desarrollo moral desde su raíz, desde el sentido originario y más profundamente humano de la moral, o desde la naturaleza constitutivamente moral de cada uno de nosotros como ser humano. Y se trata, en tercer lugar, de exponer desde un planteamiento psicopedagógico, las implicaciones teóricas y prácticas que requiere y ha de elaborar la concepción y la realización de un desarrollo moral íntegro.

Este planteamiento responde a una distinción básica: una cuestión es entender el desarrollo íntegro del ser humano hasta su plenitud posible — cabe avanzar que esta es la tarea que caracteriza a la moral- y otra es el análisis y el estudio del proceso mismo vital psicoeducativo por el que se lleva a cabo esta tarea moral que es el desarrollo pleno, íntegro, del individuo en todas sus potencialidades; dicho de otra manera: entender qué es la moral, comprender su fundamento y cómo se traduce esta concepción en propuestas morales concretas es una cuestión distinta de la cuestión que plantea estudiar mediante qué procesos psicológicos, educativos, socializadores tiene lugar en el individuo esa concreción normativa y valorativa. Pues bien, entiendo que el punto de partida psicoeducativo ha de ser, no una preconcepción de la moral, sino la realidad misma de las personas como seres humanos, la naturaleza moral de las personas en su ser lo que son como seres humanos, en su existencia y en su dinámica vital. Sólo después sabemos qué es o qué puede ser la moral en general y en sus contenidos particulares: qué son normas, valores, virtudes, etc. morales y, finalmente, pensaremos de forma más adecuada qué es el desarrollo moral como desarrollo humano íntegro, de manera que puedan elaborarse rigurosamente teorías psicopedagógicas coherentes y asumibles que lo expliquen y lo orienten. 


\section{Supuestos éticos de las teorías sobre la educción moral. Una reflexión crítica}

La reflexión psicopedagógica contemporánea se ha reflejado en múltiples investigaciones y escritos, sobre todo a partir de las obras clásicas de los principales psicólogos del modelo cognitivo-evolutivo que llevaron a su madurez el planteamiento psicológico del desarrollo moral y los problemas educativos que habrían de posibilitar y orientar este desarrollo: J. Piaget y L. Kohlberg. La amplitud y el rigor de sus investigaciones fueron precedidos, no obstante, por distintas aproximaciones previas como las procedentes de la sociología de E. Durkheim, del psicoanálisis de S. Freud y de la investigación empírica de J. Baldwin, Hartshorne y May, pero también por la quizá más notable pero menos conocida exposición del desarrollo moral expuesta por J. Dewey en el contexto del pragmatismo o, mejor, del experimentalismo y naturalismo empírico como él mismo denominaba frecuentemente a su filosofía. Como ha observado J. M. a Puig Rovira, J. Dewey fue el primero que formuló las tesis básicas reelaboradas después por Piaget y desarrolladas a continuación por Kolhberg y que son de trascendental importancia en el proceso educativo: «el objetivo de la educación es el crecimiento o desarrollo, tanto intelectual como moral. Los principios éticos y psicológicos pueden ayudar a la escuela en la más grande de todas las construcciones: la edificación de un carácter libre y fuerte. Sólo el conocimiento del orden y de la relación que existe entre los estadios del desarrollo psicológico puede asegurar esto" ${ }^{1}$; tales estadios son, precisamente, los que Dewey llamaba nivel premoral o preconvencional, nivel convencional y nivel autónomo.

Continuadores inmediatos de Kohlberg, pero en una línea crítica, fueron C. Gilligan y E. Turiel ${ }^{2}$, y muy vinculados a Kohlberg están también algunos aspectos y contenidos de la filosofía de J. Habermas que señala la dependencia recí-

1 J. DEWEY, «Waht psychology can do for the teacher», Moral principles on education, en R. Archambault, comp., J. Dewey on education: selected writngs, Randon House, New York, 1964. Obras importantes para conocer su filosofía moral y teorías psicopedagógicas son: Psychology, 1887; Outlines of a critical theory of etics, 1891; The study of etics: a syllabus, 1894; My pedagogic creed, 1897; The school and society, 1900; Schools of tomorrow, 1915; Democracy and education, 1916; Human nature and conduct, 1922; Experience and education, 1938; Education today, 1940.

2 C. GILligan, In a different voice: psychological theory and women's development, Harvard University Press, Cambridge, 1982 y E. TURIEL, The development of social knowledge, Cambridge University Press, 1983. 
proca entre la filosofía moral y la psicología de la evolución de la conciencia moral, la cual fue reelaborada por Habermas en el contexto de su teoría de la acción comunicativa, proponiendo una fundamentación lógico-evolutiva de las etapas morales y de los estadios 5 y 6 postconvencionales, pero reformulados en términos ético-discursivos ${ }^{3}$.

Además de este modelo cognitivo-evolutivo conocemos otros modelos teóricos para entender desde la psicología el desarrollo moral. La psicología dinámica, principalmente según el pensamiento de S. Freud para quien «la moral y los sentimientos sociales más elevados se adquieren como consecuencia y exigencia de la superación del complejo de Edipo y como resultado de la compensación de los impulsos hostiles insatisfechos» ${ }^{4}$. El conductismo entiende la moral en términos de comportamiento. Para B. F. Skinner los modelos de conducta se adquieren mediante el aprendizaje social y se moldean y fijan por medio de las "contingencias de refuerzo» concomitantes y que son de orden social: la moral conductista se mueve totalmente en la heteronomía personal y social, y toda nuestra conducta está determinada por nuestra historia de refuerzos y contingencias. De alguna manera Miller y Dollard rompieron la rigidez de este modelo iniciando una aproximación al cognitivismo, pero la ruptura con la ortodoxia conductista es sobre todo la que llevó a cabo la Social Learning Theory desarrollada por A. Bandura, R. H. Walters, F. Mcdonald, J. Aronfreed, etc. ${ }^{5}$. La psicología humanista intenta situar la dimensión moral bajo la fuerza del yo, no del superyo, como centro consciente y de equilibrio de la personalidad. La conducta resulta de la libre opción del sujeto maduro más que de rasgos fijos o de comportamientos pasivamente aprendidos. Concretamente, Zavalloni partía de los conceptos de «unidad» y de «totalidad» como presupuesto para un estudio adecuado del hombre, y afirmaba después que «la tendencia moral del hombre está inscrita en el psiquismo», y que «es moral todo cuanto está conforme con la naturaleza huma-

3 J. Habermas, Moralbewusstsein und kommunikatives Handeln, Suhrkamp Verlag, Frankfurt am Main, 1983; trad. esp. Conciencia moral y acción comunicativa, Barcelona, Ed. Península, 1985.

${ }^{4}$ A. P. BoselLo, Escuela y valores, C.C.S., Madrid, 1998, p. 50.

${ }^{5}$ B. F. SKInNer, Más allá de la libertad y de la dignidad, Ed. Fontanella, Barcelona, 1972; A. BANDURA y R. H. Walters, Social learning and personality development, New York, 1963; A. BANDURA y F. M. MCDONALD «The influence of social reinforcement and the behaviour of models in shaping children's moral judgements», en Journal of Abn. And Social Psy., 1963, p. 274-281; J Aronfreed, «Moral development as the standpoint of a general psychological theory», en T. Lickona, ed., Moral development and behaviour, New York, 1976. 
na» ${ }^{6}$. Habría que añadir todavía, sin pretensiones de exhaustividad, el enfoque narrativo como metodología fecunda para profundizar en el sentido de la experiencia humana; metodología desarrollada más filosóficamente por P. Ricoeur, y con un planteamiento psicopedagógico por M.B. Tappan y L. M. Brown ${ }^{7}$. Y finalmente el constructivismo de autores como J. Rubio Carracedo y, de alguna manera, de J. M. a Puig Rovira.

Rubio C. piensa que, aunque la educación parezca a veces imposible, atrapada entre la socialización adaptativa y el individualismo subjetivista, se la puede plantear como tarea de una construcción dialógica de ciertas normas y pautas de conducta para resolver responsablemente los dilemas axiológicos. La educación moral hay que entenderla como autoconstitución de la persona moral, capaz de construir cooperativamente, por medio de la deliberación argumentativa y de la interacción social, juicios ponderados que luego traduce e interpreta contextual y responsablemente en su práctica habitual pública y privada. Por lo tanto, la educación moral es «un proceso de creciente maduración cognitiva, motivacional y práctica que persigue la autoconstrucción de una personalidad moral, crecientemente autónoma y responsable en sus decisiones y en su comportamiento ante las diferentes alternativas axiológicas que se le ofrecen» ${ }^{8}$. J. M. ${ }^{\text {a Puig Rovira, por }}$ su parte, entiende la moral como «una construcción que depende de cada sujeto y del conjunto de todos ellos»; consecuentemente "la educación moral como construcción pretende trabajar con los pequeños y grandes problemas morales que nos plantea la experiencia, y quiere hacerlo entrando en ellos mediante los procedimientos de deliberación y dirección moral que cada individuo va adquiriendo a lo largo de su desarrollo", analizando personal y colectivamente los problemas guiados también por los valores en cuanto ayudan a considerar los conflictos?

${ }^{6}$ A. ZaVAlloni, «La norma inscrita nello psichismo umano», Pedagogía e Vita, 1984, n. ${ }^{\circ}$ 5, p. 465 y 470 respectivamente. Zavalloni escribió una buena síntesis del pensamiento humanista en «Studio sul giudizio e sulla condotta umana», Orientamenti Pedagogici, n. 4 4, 1957, p. 808-830. Un planteamiento más amplio está desarrollado en Educazione e personalitá, Ed. Vita e Pensiero, Milano, 1955.

7 P. Ricoeur, Du texte à l'action, Paris, 1986; M. B. TAPPAN y L. M. Brown, «Stories told and lessons learned: toward a narrative approach to moral development and moral education», en Harvard Educ. Rev., n. ${ }^{\circ}$ 59, 1989, p. 182-205

8 J. Rubio CARRACEDO, Educación moral, postmodernidad y democracia, Ed. Trotta, Madrid, 1996, p. 66-7. Asimismo, Ética constructiva y autonomía personal, Ed. Tecnos, Madrid, 1996.

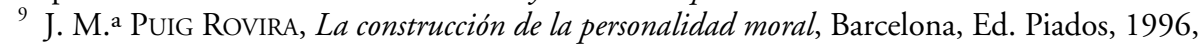
p. $70-71$. 
Otros muchos estudios se ocupan en la actualidad de plantear desde distintos enfoques y perspectivas y con distintos fines los problemas que descubre y analiza la psicología del desarrollo moral, la cual se va elaborando y exponiendo con la mayor frecuencia en estudios teóricos todavía fragmentarios en cuanto a su contenido, metodología y perspectivas demasiado particulares. Se observa, efectivamente, que con frecuencia estos estudios pedagógicos conciben explícitamente al individuo, más que en su identidad propia y singular, en su condición, asimismo real, de ciudadano teniendo en cuenta su contexto histórico, social y político o democrático; y, desde otra perspectiva, se detectan en ellos dos planteamientos que predominan en la orientación que toman estas investigaciones: a) unas tratan de impulsar como objetivo principal la autonomía moral de los sujetos, y b) otras se ocupan sobre todo de la educación moral de su carácter, actitudes, hábitos o virtudes. No se trata, evidentemente, de dos orientaciones psicopedagógicas mutuamente excluyentes — aunque a veces es muy claro el predominio de una u otra, e incluso ha sido muy llamativa en tiempos recientes la elocuente ausencia de una filosofía, psicología y pedagogía moral del carácter, de la virtud- De hecho, empiezan a ser más frecuentes los estudios comprometidos con ambas tareas, y en el ámbito de la psicopedagogía son un buen ejemplo las aportaciones de R. S. Peters. Ciertamente, Peters se ocupa de manera muy particular, por ejemplo, del carácter, cuyos rasgos están «entre las cosas que un hombre puede decidir ser»y, por lo tanto, el carácter contrasta con la naturaleza. Peters desarrolla un pensamiento de talante integrador porque la educación «trata de lograr que las personas se realicen dentro de actividades consideradas valiosas, en una forma que involucra un entendimiento de todo de cierta clase de profundidad y alcance»; la educación implica interiorizar lo que es valioso para seguirlo por sí mismo, pero también debe involucrar conocimientos y entendimiento. No obstante mi acuerdo en este punto, y en razón de lo que entiendo y desarrollo más adelante como concepción y fundamentación de la moral, no comparto sin más la idea de Peters cuando afirma que «la moral se refiere a las razones existentes para hacer o no hacer algo, para crear o eliminar ...»" ${ }^{10}$.

a) Tratan la autonomía, evidentemente, las teorías educativas de orientación cognitivo-evolutiva, pero también, por ejemplo, J. Delval e I. Enesco

10 R. S. PETERS, Desarrollo moral y educación moral, Madrid, F.C.E., 1984, p. 29 y 56, respectivamente. Hallamos aportaciones interesantes en este sentido en W. C. BERKOWITZ, Educar la persona en su totalidad, Barcelona, F.C.E., 1996. 
cuando se ocupan de la libertad, o E. Guisán explicándonos que «la ética nos enseña a transitar de la moralidad positiva a la moralidad crítica o, lo que es igual, de la moral que nos imponen los agentes socializadores a una nueva moral que diseñamos en diálogo intersubjetivo que la actividad filosófica propicia», para instalarnos en el ámbito de la autonomía ${ }^{11}$. Hay que señalar, por el contrario, que las teorías morales heterónomas están afectadas generalmente de un irracionalismo más menos pronunciado, como es el caso de la concepción de la psicología dinámica freudiana o del conductismo. Al otro lado está la racionalidad autónoma del juicio moral.

b) Respecto al segundo grupo de teorías de la educación moral, abundan ya los estudios psicopedagógicos a la vez que la filosofía moral ha recuperado, en sintonía con la tradición filosófica, pero también con innovaciones originales, la reflexión sobre los valores, la virtud, la felicidad, etc. Se caracteriza este paradigma, según Puig Rovira, por la convicción de que una persona no es moral si únicamente conoce intelectualmente el bien; es necesario que mantenga una línea de conducta virtuosa: que realice habitualmente actos virtuosos dirigidos al bien y a la felicidad, porque sin la formación de hábitos virtuosos y la configuración del carácter no hay personalidad moral ${ }^{12}$.

Un punto común de estas teorías es la coincidencia en sus críticas al proyecto ilustrado de la modernidad, en cuanto a su pretensión de imparcialidad y a su formulación de propuestas vacías de contenidos normativos y valorativos. Neoaristotelismo y comunitarismo critican el programa racionalista, universalista y liberal de las éticas y de las políticas de la modernidad porque ha perdido la noción de virtud y de carácter como una «manera adecuada de ser». Es prioritario desarrollar las «virtudes» y una personalidad «buena», formar «actitudes» entendidas como «aquellas tendencias y predisposiciones aprendidas y relativamente fijas

${ }^{11}$ J. DelVAl e I. Enesco, Moral, desarrollo y educación, Ed. Anaya, Madrid, 1994, y E. GuISIÁN, Introducción a la ética, Ed. Cátedra, Madrid, 1995.

${ }^{12}$ J. M. a Puig Rovira, op. cit. Además de los autores citados ahora, pueden consultarse L. P. NuCCI, comp., Moral development and caracter education, Berkekey, McCutrahan Publ. Corp., 1989, y J. A. JORDÁN SANABRIA y F. SANTOLARIA, comps., La educación moral hoy. Cuestiones y perspectivas, Ed. PPU, Barcelona, 1992. 
que orientan la conducta que previsiblemente se manifestará ante una situación u objeto determinado» ${ }^{13}$. Todo lo cual requiere establecer y definir un telos, una finalidad cuya realización oriente y conduzca la conducta y la vida individual. A este respecto, precisa V. Camps de acuerdo con su punto de vista moral que educar es formar el carácter "para que se cumpla un proceso de socialización imprescindible, y formarlo para promover un mundo más civilizado, crítico con los defectos del presente y comprometido con el proceso moral de las estructuras y actitudes sociales. A eso, a la formación del carácter, es a lo que los griegos llamaban ética». Y en otro momento continúa: «no progresarán los ideales éticos si no cambian las actitudes personales», añadiendo en otro lugar que es necesario reconstruir la moral como conjunto de virtudes así como «una ética de actitudes e inclinaciones individuales dirigidas a hacer más justa y digna la vida colectiva» ${ }^{14}$. De manera análoga, A. Heller reivindica las virtudes entendidas como «rasgos del carácter que son considerados ejemplares por una comunidad de personas», y se adquieren por una práctica correcta, consecuente y continuada; concretamente, las virtudes cívicas son las del ciudadano como tal, independientemente de su credo, profesión, gustos, etc. y sus contenidos son los bienes compartidos relacionados con la res publica, con la «cosa común» de Cicerón, "considerados como condiciones de bienestar»"

Finalmente, el principal representante del neoaristotelismo actual, Alasdair MacIntyre, propugna una ética de la virtud entendida como una cualidad humana adquirida referida a una "práctica», que implica un bien intrínseco a la misma; este bien resulta de la mayor excelencia del sujeto, es accesible a todos y su logro es un bien para la comunidad. Pero la virtud conlleva modelos de excelencia y obediencia a reglas. Ahora bien, sin la definición de un telos dominante de la vida humana completa, como unidad, la concepción de ciertas virtudes es parcial e incompleta, pues los bienes internos a las prácticas necesitan jerarquizarse ya que, a veces, se trata de demandas incompatibles: es necesario un telos

${ }^{13}$ Id., La educación moral en la enseñanza obligatoria, p. 125.

${ }^{14}$ V. CAMPS, Los valores de la educación, Ed. Alauda, Centro Pedagógico para el Desarrollo de la Reforma Educativa, Madrid, 1993, p. 11 y 106; asimismo Virtudes públicas, Espasa Calpe, Madrid, 1990, p. 11. En la línea de las ideas que estoy refiriendo es sugerente la lectura de M. KILlEn y D. HART, Morality in everyday life, Cambridge Univ. Press, 1995, y desde otra perspectiva A. ARTETA, La virtud de la mirada. Ensayo sobre la admiración moral, Pre-textos, Valencia, 2002.

15 A. Heller, «Etica ciudadana y virtudes cívicas», en A. Heller y F. FeHér, Políticas de la postmodernidad. Ensayos de crítica cultural, Ed. Península, Barcelona, 1989, p. 219 y 221. 
que justifique postergar a un bien otros bienes considerados secundarios respecto a ese telos, de otra manera habría arbitrariedad moral ${ }^{16}$.

Vinculado estrechamente a estas morales del carácter, actitudes, hábitos o virtudes, debería estar el concepto de felicidad que, a mi modo de ver, es elemento esencial o núcleo de la filosofía moral y de suma importancia teórica y práctica; sin embargo, está poco presente en las teorías psicopedagógicas actuales del desarrollo moral: hoy se tiene la impresión de que los mismos filósofos se preocupan más por el bienestar y por la justicia, o por la justicia como condición del bienestar; más por las condiciones externas y por el disfrute de un modo o nivel de vida, que por las condiciones y por la vivencia internas de la felicidad, y más por la realización de la justicia en la sociedad del bienestar, que por el desarrollo de la solidaridad en la comunidad humana. Y no es por casualidad que todo esto ocurra así, porque creo que predomina hoy una concepción de la moral excesivamente extrínseca al hombre, sin su referencia esencial a las personas en sí mismas, sino más favorable a la objetivación de los sujetos morales en tanto interactuantes y ciudadanos que como seres humanos. A esta dimensión moral constitutiva de la naturaleza humana, intrínseca e inherente a ella aludía al principio; y a su transformación y versión, tan generalizada, en conceptos sociales y sociológicos apunta mi crítica. Porque, ciertamente, la moral tiene inevitablemente un fundamento antropológico, a toda concepción filosófica de la moral subyace una concepción del hombre. Pero es que hoy, más que de una concepción del hombre como tal, parece tratarse de una concepción del hombre social o de una concepción social del hombre; por lo tanto, se tiende a pensar la moral, y según ella la psicología moral y la educación moral, como fundadas en una determinada concepción de la sociedad, de sus distintas organizaciones, instituciones y estructuras, desde la sociedad familiar y escolar a la sociedad internacional, como si éstas fueran el verdadero sentido y fundamento de la moral y de las teorías de la psicopedagogía moral. No es extraño, por lo tanto, hallar implícita en estas teorías psicopedagógicas lo que sería una moral meramente social, es decir, una moral que ya no es tal porque ha sido reducida a sociología, a sociología de las normas, valores, virtudes «sociales», de interrelación y vinculación social; sin embargo, una cosa es la moral y otra bien distinta el estudio sociológico de la moral, como también es distinto de la moral su estudio desde cual-

16 A. Macintyre, After virtue, Notre Dame, Indiana, University of Notre Dame, 1984, p. 236 y ss.; trad. esp. Tras la virtud, Barcelona, Ed. Crítica, Barcelona, 1987. 
quier otro enfoque psicológico, educativo, teológico, etc. Así, son reduccionistas e insuficientes porque no se centran en el hombre en su unidad y totalidad propuestas como las de J. Delval e I. Enesco cuando firman que «los problemas de la moral se plantean porque los hombres viven en sociedad»y, por lo tanto, los hombres «necesitan reglas que dirijan su acción respecto a los demás», o que "cada sociedad posee una serie de normas acerca de las conductas deseables e indeseables» $y$, finalmente, que «la sociedad presta una gran atención a que adecúe su conducta a las normas compartidas. Ninguna sociedad carece de esas normas compartidas, que constituyen lo que se denomina la moral o la ética» ${ }^{17}$.

También en J. M. a Puig Rovira hay una reducción de la moral a sociología moral: «la moral no es algo dado de antemano, presupuesto o que simplemente se decide o elige, sino que la moral es, pues, un producto cultural cuya creación depende de cada sujeto y del conjunto de todos ellos». Y en la misma línea A. Heller entiende que «la moral puede ser descrita del mejor modo como la relación práctica del individuo hacia las normas y reglas de buena conducta», de manera que «no hay ninguna esfera o institución que tenga un carácter puramente moral. Todas ellas incluyen ciertas normas que pertenecen a la Sittlichkeit». Tampoco es defendible totalmente la posición de A. MacIntyre asumiendo, a su manera, una idea aristotélica: «no puedo perseguir mi bien de ninguna manera que necesariamente sea antagónica del tuyo, porque $e l$ bien no es peculiarmente mío ni tuyo, ni lo bueno es propiedad privada. De aquí la definición aristotélica de la amistad, la forma fundamental de relación humana, en términos de bienes que se comparten».

Respecto a las corrientes psicopedagógicas antes mencionadas, caben también objeciones críticas en otros aspectos. En primer lugar, revelan, respectivamente, una concepción del hombre que lo convierten en un ser humano monográfico, reducido a algunos de sus elementos constitutivos, pero ignorando otros igualmente esenciales. Particularizando algunos aspectos concretos, asumo las principales críticas al modelo cognitivo-evolutivo porque, en definitiva, sólo pretende garantizar la autonomía de un sujeto dotado del desarrollo racional que le haga capaz y apto para decidir sus opciones y conducta moral katá ton órthon lógon, aunque no con todo el contenido aristotélico de esta expresión. El con-

${ }^{17}$ J. Delval e I. ENESCO, op. cit., p. 289. 
ductismo deja al hombre sin interioridad, reducido exteriormente a un conjunto de estímulos y respuestas, al mecanismo de un procesamiento de acciones y reacciones en el contexto de su aprendizaje social. La psicología dinámica freudiana reduce lo fundamental del hombre a una monopulsión libidinosa, entre eros y thánatos, que acaba racionalizando su complejo de culpa mediante la interiorización sublimada de los imperativos paternos y sociales en la conciencia del super-yo. La psicología humanista, finalmente, afirma el yo, su racionalidad, su libertad y su voluntad, su autodesarrollo, pero no, como pretende, en su unidad y totalidad porque tiene poco en cuenta la dimensión sociocultural del ser humano, en su existencia y en su vida cotidiana.

Claro está que esta crítica iniciada ahora remite y se apoya en los supuestos ético-antropológicos ya aludidos varias veces. Tal alusión resulta ya insuficiente y requiere un mínimo desarrollo de tales supuestos. Se trata aquí, desde la reflexión filosófica, tan sólo de esbozar las líneas generales de una concepción y fundamentación antropológica de la moral que permita entender de manera adecuada la idea y la tarea vital, existencial, del desarrollo integral del ser humano y, por lo tanto, del desarrollo moral íntegro así como, en consecuencia, sus contenidos psicológicos y sus exigencias educativas.

\section{Concepto y fundamento antropológico de la moral y del desarrollo moral como desarrollo humano}

Frecuentemente se han hecho cargo los filósofos de la necesidad de definir y precisar cuestiones como el sentido de la moral, sus contenidos normativos y valorativos, sus fines y medios adecuados, su realización individual y su dimensión social, etc. y de la necesidad de asentar todo ello sobre razones sólidas mediante una argumentación racional, intersubjetiva, universalizable, etc. según los casos. Pues bien, entiendo, en primer lugar, que la cuestión del concepto de la moral y la cuestión de su fundamento, siendo formalmente diferentes, son materialmente inseparables y se remiten recíprocamente una otra; y entiendo asimismo, en segundo lugar, que las respuestas a ambas cuestiones requieren una referencia ineludible a la naturaleza humana en cuanto es su última razón de ser y su fundamento más radical. La primera tesis, que relaciona concepto y fundamento, es bien patente e indiscutible. La segunda tesis, que pone como sentido y fundamento de ambas la naturaleza humana misma, deja de ser clara y 
objetiva ya que, aun siendo constatable en toda la historia del pensamiento moral a penas la han afirmado explícitamente los filósofos alguna vez, e incluso ha sido a veces rechazada. Sin embargo, frente a quienes eliminan toda alusión directa a la «naturaleza» humana — cuando implícitamente está contenida y sustentando de manera bien patente las afirmaciones éticas de quienes la rechazan, si es que éstas han de tener una razón de mayor peso que los tópicos al uso- es imprescindible contar con esta naturaleza humana como la referencia más específica y radical de todo lo que pueda ser entendido como «moral» en cualquiera de sus contenidos; por otra parte, durante más de veinticinco siglos sólo en referencia al ser humano se ha entendido la moral y sólo él es una ser moral. Pero sólo puede serlo en razón de lo que lo distingue de los demás seres naturales, es decir, en razón de su específica naturaleza humana. Esto es lo decisivo, porque qué sea la moral ya sólo puede entenderse en términos de la naturaleza humana, en función de qué sea la naturaleza humana o de cómo es el hombre por naturaleza, independientemente de las teorías preconcebidas o de ideas elaboradas de acuerdo con otras referencias que hayan pensado o supuesto los filósofos, psicólogos, sociólogos o educadores. No hay moral, decía antes, porque hay «moralistas» que piensan teorías morales, sino por la naturaleza moral del hombre y sólo en razón de su naturaleza específica entendemos que el hombre es un ser moral y qué es la moral misma. Otra es la cuestión de qué sea una concepción adecuada de la naturaleza humana: ese es el problema filosófico de pensar y desarrollar una antropología que se haga cargo del "problema del hombre» y del «hombre como problema».

Bien cerca tenemos en la filosofía española contemporánea una digna muestra de esta ética antropológica, como es la del profesor José Luis L. Aranguren. En su prólogo a Ética mínima, de A. Cortina, Aranguren anunciaba y denunciaba que estamos en tiempos de una ética intersubjetiva más que de ética intrasubjetiva; antes predominaba una moral individual y de la felicidad, centrada en la reflexión sobre la persona, y hoy está en primer plano una moral social centrada en la justicia, una moral política, médica, etc. Aseguraba Aranguren que una moral social no puede olvidar la moral personal, así como que estudiar qué es una sociedad justa no debe bloquear la investigación sobre la felicidad. Y tiempo atrás había explicado la distinción bien conocida entre moral como estructura y moral como contenido, en la línea del pensamiento de X. Zubiri, de su concepto de la sustantividad humana y de su concepción del hombre y de la moral. Según Zubiri, lo que en parte justifica las preferencias y elecciones 
de cada uno son las tendencias inconclusas de su constitución temperamental natural ${ }^{18}$.

Tales ideas desarrollan de una manera particularmente original y crítica temas de la tradición tomista y neoaristotélica, fuente primera ésta última de ideas muy fecundas hoy. Pues bien, la ética de Aristóteles es una ética de la felicidad, y en función de ella estudia el tema de la bondad y de las virtudes, de la amistad, etc.; pero importa reconocer que la filosofía de Aristóteles expone una concepción antropológica de la amistad, de las virtudes, de la bondad y de la felicidad; es decir, de la moral.

Sócrates entendía que la felicidad es el bien supremo del hombre, y Platón hizo de ella algo puramente ideal pues determinó su contenido recurriendo a un mundo trascendente; pero Aristóteles afirmaba que el fin supremo de la actividad humana debe ser inmanente, que el bien moral es el bien para el hombre según su específica naturaleza y que, por lo tanto, la felicidad resulta sólo de la actividad del alma según las virtudes que le son propias. La felicidad es el bien supremo, un bien específico propio, perfecto, definitivo y completo; lo mejor, lo más bello y lo más agradable constituyen el acto más perfecto del hombre: la eudaimonía, el mejor de los bienes del alma. Pero la felicidad no resulta del azar ni es un don de los dioses, sino que es actividad del alma de acuerdo con la virtud mejor y más perfecta durante una vida entera, y que, además, se obtiene por la práctica de la virtud mediante cierto aprendizaje, como realización de lo característico de la naturaleza humana, de sus facultades espirituales, de lo divino en el hombre: la felicidad es enérgueia theoretiké. Ahora bien, el hombre feliz — makários - está provisto suficientemente de bienes externos a lo largo de su vida, aunque no depende su felicidad de las vicisitudes de la fortuna ${ }^{19}$.

${ }^{18}$ Algunas de estas referencias están en A. CoRTinA, Ética minima, Madrid, Ed. Tecnos, 1986 y El quehacer ético. Guía para la educación moral, Ed. Santillana, Madrid, 1996. Pero sobre todo José Luis Aranguren, Ética, Madrid, Ed. Revista de Occidente, 1958 y su Propuestas morales, Madrid, Ed. Tecnos, 1984, así como X. ZuBiRI, Sobre la esencia, Madrid, Sociedad de Estudios y Publicaciones, 1963, y Sobre el hombre, Madrid, Alianza Ed., 1986.

19 Aristóteles, Etica a Nicómaco, 1094 a - 1102 b y 1176 a 30 - 1181 b 24; traducción y notas de J. Pallí Bonet, introducción de E. Lledó, Ed. Gredos, Madrid, 1985. Asimismo, importan estudios como los de P. AubENQue, La prudencia en Aristóteles, Ed. Crítica, Barcelona, 1999; Marta Nussbaum, La fragilidad del bien, Ed. Visor, Madrid, 1995; E. Lledó, Memoria de la ética, Ed. Taurus, Madrid, 1994; C. Thiebaut, Cabe Aristóteles, Ed. Visor, Madrid, 1988; W. D. Ross, Aristóteles, Ed. Sudamericana, Buenos Aires, 1957. 
Filosofías morales como muchas de las desarrolladas desde Aristóteles hasta Aranguren son muy razonables, pero me parecen insuficientes desde una perspectiva antropológica porque el hombre no se reduce a lo específicamente humano del género animal, como lo contempla Aristóteles, ni la moral se reduce a la estructura de la naturaleza humana, sino que ésta tampoco se distingue del contenido de la moral, y esto es lo que no encuentro desarrollado por Aranguren. Por mi parte, en lo más esencial y muy brevemente, pienso lo siguiente.

La realidad más empírica del hombre nos hace percibirlo y entenderlo a) como un ser imperfecto, incompleto, no terminado desde el principio, o no hecho del todo desde su nacimiento; b) como desvinculado, liberado o no sujeto al determinismo instintivo que caracteriza a los demás seres vivos y, como contrapartida, dotado de capacidad racional, abstracta y simbólica; c) como un ser que no se agota ni se acaba en sí mismo, sino que es un ser abierto, de naturaleza abierta y receptiva, que en su inminencia es trascendente a lo otro de sí y, sobre todo y más específicamente, a los otros hombres hallándose todos, precisamente por eso, más o menos inmediatamente, pero necesariamente, implicados entre sí; y d) compartiendo cada ser humano con los demás éstas y todas las demás cualidades específicas de la naturaleza humana, de manera que los hombres son iguales por o en su naturaleza y la naturaleza humana es igual y la misma en todos lo hombres. Por lo tanto, estas características, entre otras, constitutivas del ser humano son las que llevan a caracterizar y a entender la moral, e inducen a un concepto de la moral según el cual ésta consiste y se define como plena auto-co-realización de cada uno según su naturaleza humana individual; o simplemente moral como autorrealización, porque todo lo que podemos añadir son rasgos y contenidos que precisan y hacen más explícita la realidad de esta autorrealización. Es decir, cada uno es sujeto natural y moral de su propia existencia como proyecto y tarea vital, sujeto primero y último, pero no único. Así, su desarrollo humano es desarrollo humano y moral en su integridad, y su realización es realización humana y moral hasta su plenitud posible. Consecuentemente, la moral expresa normativamente lo que el hombre es constitutivamente; y como el hombre es siempre caminante, un ser in fieri, la moral expresa axiológicamente, valorativamente, lo que el hombre por su naturaleza aspira a ser, lo que el hombre necesita ser, cómo necesita vivir, dada su naturaleza humana, para su plena autorrealización. Las dimensiones y funciones normativa y axiológica de la moral son, por lo tanto, correlativas; incluso norma y valor, en su expresión más formal y universal, coinciden en un mismo contenido antropológico y moral: la plena y feliz autorrealización del individuo. 
Observamos efectivamente en la experiencia cotidiana que la moral de hecho, la moral vivida, es siempre valorativa y reguladora de la conducta y de las acciones de las personas, pero también es necesariamente normativa: son distintos aspectos de una misma realidad moral. Ahora bien, la normatividad y la axiología morales no pueden interferir el pleno desenvolvimiento de la naturaleza humana en su unidad y totalidad, ni obstaculizar o limitar el desarrollo total de todo lo que constituye al individuo como ser humano y como el ser humano singular que él es, porque si el contenido de la moral entorpeciera su plena autorrealización sería, evidentemente, inhumano y por lo tanto inmoral, haría contradictoria la moral, la cual no pasaría de ser una pseudo-moral social, etc. La moral no puede impedir el desarrollo humano ni recortarlo, sino asumirlo, procurarlo y potenciarlo; sus contenidos normativos y valorativos han de coincidir con los de la naturaleza viva humana individual que es cada ser humano, cada persona; todo lo que la moral es se constituye como cualidad o dimensión ontológica del ser humano, de la naturaleza humana de cada sujeto y, por lo tanto, los contenidos y potencialidades del ser humano ya no son sólo contenidos naturales sino que por serlo son también morales. Este concepto de la moral está reforzado y consolidado por el concepto correlativo de su fundamento, como ahora vamos a ver, lo mismo que éste lo está por el concepto.

De acuerdo con el concepto antropológico de la moral, enuncio su fundamento real o fáctico en síntesis diciendo: todo y sólo lo que esencial al hombre es asimismo esencial a la moral; es decir, todo y sólo lo que es contenido y característica propios de la naturaleza humana es también contenido y característica de la moral, lo que es natural al hombre es lo que constituye la naturaleza de la moral. La moral no necesita ni puede añadir nada porque haría de la naturaleza humana otra cosa; la moral, por lo tanto, contempla y ordena los elementos constitutivos de la naturaleza humana dentro y en función de su unidad y totalidad, para posibilitar la realización de la plenitud del ser humano vivida como felicidad Pero la naturaleza humana, de hecho, es lo que sabemos que es, es lo que entendemos como naturaleza humana, es siempre un constructo cultural, no una realidad nouménica. La naturaleza humana es la autoconcepción que el hombre de una época tiene de sí mismo, la autocomprensión sociocultural del hombre. Y entonces, entiendo que el fundamento antropológico de la moral consiste teóricamente en que toda concepción de la moral implica una concepción del hombre, es decir, remite, plantea y se basa en una concepción del ser humano, de su naturaleza y de sus contenidos. 
Concepto y fundamento antropológico de la moral, a partir de ahora, se constituyen por eso mismo en criterio de demarcación de lo que es propiamente moral respecto de lo que no es moral, sino otra osa; determina lo que es contenido de la moral y qué cuestiones son verdaderamente cuestiones morales, de manera que, inversamente, todo concepto moral, toda problema moral y toda teoría moral que no sea o no incluya un contenido o cuestión antropológica en el sentido del concepto y fundamento indicado, no es verdadera y estrictamente moral. Dicho de otra manera: siendo la plena auto-co-realización el núcleo esencial de la moral, el imperativo más formal y el valor más universal, sólo es moral un concepto, cuestión o teoría si y en cuanto su contenido tiene que ver con la autorrealización personal en su sentido ontológico y existencial o vital. Lógicamente, los rasgos de la moral se derivan necesariamente de la naturaleza humana individual de las personas y vienen determinados por ella. Así, por ejemplo, la dialecticidad de la naturaleza humana, y por lo tanto de su autorrealización, determina y fundamenta la dialecticidad de la moral y es criterio de la dialecticidad de sus contenidos y de la educación en los mismos: de la bondad y perfección, de las normas, valores y virtudes, la felicidad, carácter, libertad, actitudes, así como de la solidaridad entendida como realidad y dimensión socio-comunitaria del hombre y de la moral. La realización de esta moral antropológica manifiesta, como veremos más adelante, la necesidad de una verdadera transmutación de los valores predominantes de nuestra cultura en valores fácticos verdaderamente humanos, es decir, de los valores sociopolíticos, por ejemplo, en valores verdaderamente morales, auto-co-realizantes; es necesario moralizar en este sentido la vida privada y la vida pública y comunitarizar la sociedad, transformar la sociedad en una auténtica comunidad humana, en la que sea posible la plena autorrealización individual correalizada y felizmente convivida. En esto consiste, además, la necesidad de moralizar, profundizar y democratizar la democracia.

Frecuentemente las teorías psicopedagógicas que se ocupan del desarrollo moral son teorías sectoriales sobre algunos aspectos o elementos comprendidos realmente en el desarrollo moral. No obstante, es evidente la necesidad imprescindible de contar con una teoría integral del desarrollo moral que, efectivamente, integrase los distintos modelos y planteamientos de las teorías parciales, pero teniendo en cuenta, claro está, que esta teoría no podría reducirse a un mero eclecticismo, sino que ha de consistir en una nueva teoría con su propia fundamentación, y pensada y desarrollada de acuerdo con las exigencias epistemológicas particulares de su nuevo contenido. Esta sería la nueva teoría psicopeda- 
gógica integral en la que educar el desarrollo moral como desarrollo humano íntegro y pleno. Para ello habría de contar necesariamente con una filosofía moral antropológica como la que aquí he resumido. A partir de ella, la psicología y la pedagogía, la educación moral en definitiva, han de ocuparse del análisis de estas virtudes, actitudes, normas, etc. morales teniendo en cuenta su función en el desarrollo moral y humano pleno e íntegro y cómo lo condicionan y posibilitan, ofreciendo propuestas educativas teniendo en cuenta la naturaleza racional y emocional del hombre, la dimensión cultural, social y comunitaria del ser humano, es decir, de su plena auto-co-realización y de su felicidad.

\section{Implicaciones psicopedagógicas de un desarrollo moral íntegro: la educación moral}

El desarrollo humano y moral del individuo implica, dada su fundamentación antropológica, un modelo antropológico de la educación y de la psicopedagogía moral. Más adelante expongo una idea general de sus características, pero antes me parece oportuno hacer un breve comentario crítico y global a distintas concepciones de la educación moral poniendo de manifiesto su insuficiencia o su parcialidad desde el punto de vista de su fundamentación antropológica, partiendo de la distinción entre una concepción humana de la moral y una concepción ética, moralista o autorreferencial de la moral. Se trata de lo siguiente.

\subsection{Concepción humana y concepción ética de la moral}

Hay acuerdo muy generalizado en pensar que la educación moral se dirige al desarrollo de la personalidad moral del sujeto, a moralizar a las personas ensenándoles determinados contenidos y a desarrollar unas actitudes y la capacidad racional de juicio crítico que hagan de ellas personas con profundo sentido moral, conscientes de sus obligaciones morales, responsables de sus decisiones y comportamientos morales, capacitadas para la vida social y democrática y para su mejoramiento en el sentido de la justicia, valores comunes de la comunidad, etc. Creo, en cambio, que es ésta una concepción todavía superficial, que no acaba de ir al fondo de los problemas y planteamientos morales, al fondo de lo que es la educación moral porque no capta o no expresa el verdadero contenido y consistencia de la moral misma. La moral trata necesariamente de la persona huma- 
na en cuanto empieza y acaba en ella, trata del individuo concreto como ser humano que es, de lo humano del hombre, de humanizar al hombre realizando íntegramente sus potencialidades, toda su naturaleza humana, pero desarrollándola de la manera como es humano el hombre, a la manera de su naturaleza humana. La moral es, en primer lugar y ante todo, la realidad humana de cada persona, el modo de ser real, específico y originario del ser humano como tal y en todas sus dimensiones y, en definitiva, la tendencia innata, espontánea e ineludible de la naturaleza humana a la autorrealización del yo. La moral es, nada más y nada menos, moral del hombre y para el hombre, y su contenido y su objetivo sólo puede ser el hombre mismo y la autorrealización recíproca de los hombres en plenitud vivida y convivida como felicidad. Pensar así la moral, en su inmediata realidad, es pensar una concepción humana de la moral.

Todo lo demás, consecuentemente, no es la moral primera y fundamentalmente. La moral no es, primeramente, la historia de la moral, el desarrollo y discusión de los conceptos, cuestiones y teorías morales; ni es el estudio de los valores, virtudes, actitudes, deberes, etc. ni se ocupa ante todo de los juicios morales o de la capacidad de razonamiento moral, ni es, fundamentalmente, la aportación de la reflexión filosófica, sociológica o psicológica actual al desarrollo de las teorías morales. La moral no se ocupa del paradigma moral de una persona ideal que apenas se identifica con la persona humana concreta que se autorrealiza en su vida de cada día. La moral no puede ser, ella misma ni cualquiera de sus contenidos, su propio objeto ni su propio objetivo; la moral no es autónoma respecto al sujeto, respecto al ser humano y a la persona concreta que es su principio y su fin; no es autónoma ni prioritaria la moral y, por lo tanto, tampoco lo es ninguno de sus contenidos como la justicia, el carácter moral, qué sean las normas morales, etc. Pensar, en cambio, la moral como si fuera su propia historia, su propio objeto, autónoma respecto al sujeto, etc. es pensarla de una manera irreal, vacía de su contenido y referencia propios, como mero constructo teórico; pensar así la moral es pensar una mera concepción ética de la moral, es pensar una concepción moralista o autorreferencial de la moral. Pero así entendida, la moral carece de sentido, no es en sí misma nada excepto mero discurso mental y mera construcción teórica, aunque a veces parezca interesante.

También es cierto, no obstante, que no sólo es conveniente sino incluso necesaria una reflexión racional y discursiva sobre la moral en su realidad inmediata, y que es imprescindible comprender la naturaleza moral del hombre y la moral 
misma. Así se ha hecho desde la antigüedad hasta nuestros días; pero se ha hecho invirtiendo la prioridad de la naturaleza humana sobre la teoría de tal manera que el resultado histórico ha sido pensar la moral y entenderla como un discurso autónomo regido por su propia lógica, como disciplina y reflexión filosófica, sociológica, psicológica a la que debe acomodarse la acción y la vida del hombre. Pero así como el físico siempre tiene presente la realidad física con la que trabaja, y es consciente en todo momento de que trabaja, investiga y habla con y sobre cosas físicas reales, sobre la naturaleza física real de las cosas; así como el discurso biológico acerca del hombre se refiere siempre al ser humano como bios, como ser viviente, y habla necesariamente de la naturaleza humana como naturaleza viva, así también hay que tener presente siempre que la moral, que trabajar, investigar y hablar sobre la moral y los problemas morales, sólo puede consistir en hablar directa y expresamente sobre las personas reales, sobre los seres humanos, sobre su vida como autorrealización de sus potencialidades naturales, sobre la naturaleza humana y sobre la naturaleza humana individual de cada uno: hablar de moral no es primeramente hablar de conceptos y de teorías morales, sino hablar del ser humano como ser naturalmente moral, de su plenitud y de su felicidad real, con todas sus implicaciones filosóficas, educativas, sociológicas, etc. en cuanto necesarias en y para la plena autorrealización del ser humano según su naturaleza humana. Así, por ejemplo, hablar de normas, valores, desarrollo moral, no es hablar de normas, etc. definidas y establecidas previamente con independencia del sujeto y que éste halla necesariamente de asumir y cumplir. Podemos preguntarnos: ¡tal norma es verdaderamente una norma moral?, ¿̨la moral es autónoma o heterónoma, es universal, objetiva, subjetiva ...? ¿̨hay, y qué serían, virtudes y acciones virtuosas?, etc. Son cuestiones morales que no se resuelven ni se responden estando más de acuerdo con Aristóteles que con Kant, apoyándose en Habermas o en Rorty o introduciendo correcciones en un sentido o en otro. No se resuelven así porque la referencia crítica primera y definitiva de estas cuestiones no es Aristóteles, Kant, Habermas o Rorty, sino el ser humano y su naturaleza humana y la felicidad de su autorrealización ${ }^{20}$.

${ }^{20}$ Dice, por ejemplo, Habermas: el principio de solidaridad «tiene su raíz en que cada uno tiene que hacerse responsable del otro, porque todos deben estar igualmente interesados en la integridad del contexto vital común del que son miembros», y añade enseguida: «la justicia se refiere a la igualdad de la libertad de los individuos que se determinan a sí mismos y que son irremplazables, mientras que la solidaridad se refiere al bien, o a la felicidad de los compañeros hermanados en una forma de vida intersubjetivamente compartida ... Las normas morales no pueden proteger lo uno sin lo otro, es decir: no pueden la igualdad de los derechos y las libertades de los individuos sin el 
La concepción ética de la moral se ocupa de ciertos contenidos, con un método y planteamientos que son los propios de una moral o sistema ético determinados, que pueden no coincidir con los contenidos de la moral según su concepción humana —esto es lo grave-y que, por otra parte, chocan frecuentemente con los de otras concepciones éticas o moralistas de la moral. Y ahí tenemos, entonces, al ser humano a merced de las discusiones de las distintas teorías morales y la propia vida de uno puesta angustiosamente en juego ante opciones teóricas diferentes y problemáticas, pese a que ninguna moral moralista autorreferencial puede aportar una razón definitiva, una justificación última, distinta de sí misma, para fundamentar incuestionablemente sus propuestas y sus exigencias morales y, en definitiva, su concepción de la moral.

La concepción humana de la moral resuelve estas dificultades, si no definitivamente, sí de manera más crítica y segura porque verdaderamente va al fondo de los problemas prácticos, morales y humanos de autorrealización plenificante de las personas en su vida cotidiana, así como de las cuestiones teóricas, y porque es de mayor potencia transformadora ya que implica exigencias más profundamente humanas, más ineludibles y comprometidas de realización personal, de cumplimiento y perfección de sí mismo y de los demás, y de transformación y moralización de la vida social y política. La moral humana, no la moral moralista o autorreferencial, da razón de todo ello porque cuenta con el único fundamento real y racional incuestionable: el hombre mismo; no otra teoría

bien del prójimo y de la comunidad a la que éstas protegen», "Justicia y solidaridad» en APEL, CORTINA, alii, eds., Ética comunicativa y democracia, Ed. Crítica, Barcelona, 1991, pp. 175-205, p. 198. La distinción no es totalmente adecuada porque es insuficiente pensar que la solidaridad se refiere y se limita al bien y a la felicidad de los compañeros, en el sentido en el que entiende Habermas estos conceptos. Habermas, desde una concepción ética o autorreferencial de la moral, de la solidaridad y de la justicia, no ha captado ni ha entendido el verdadero sentido de fondo, el contenido y el fundamento no sociopolítico, sino onto-antropológico de la solidaridad y que ésta, así entendida, abarca y se refiere a todos los aspectos, dimensiones y contenidos de la naturaleza humana del individuo y de todos los individuos en su correalización recíproca; la solidaridad, por lo tanto, incluye también los mismos contenidos de la justicia: ocurre, sin embargo, que lo que la moral y la solidaridad moral no pueden garantizar y asegurar mediante el libre compromiso de cada individuo, lo ha de hacer, o al menos lo ha de paliar, coactivamente el derecho mediante la justicia.

Mi crítica vale en general para muchas otras concepciones de la justicia y de la solidaridad, análogas desde mi planteamiento, como R. DWORKIN, Taking rights seriously, London, Gerald Durkworth, Barcelona, 1977, o Foundations of liberal equality, University of Utah Press, 1990; así como V. CAMPs, Virtudes públicas, Espasa Calpe, Madrid, 1995, o J. RubIO CARraCEDO, «El paradigma ético: justicia, solidaridad y autonomía» en Philosophica Malacitana, 7, 1994, pp. 127-146. 
moral, sino la naturaleza humana misma. Podrá haber aquí, y de hecho las hay muy encontradas, discrepancias acerca de esta naturaleza humana, acerca de qué es el hombre; pero éste es ya otro problema, y también habrá que resolverlo. Importa sobre todo reconocer el ser humano como fundante de la moral: porque la moral es moral del hombre y para el hombre, porque se trata de la vida humana de cada individuo - ya que no es lo mismo que una persona haga de su vida y de sí misma una u otra cosa, en función de una u otra concepción de la moral asumida-. El hombre mismo es el único criterio, su naturaleza humana es lo único que puede decir algo, y algo tendremos que saber de verdad sobre esta naturaleza humana del hombre para decidir cómo vivir nuestra vida de la manera más plenamente humana y más verdaderamente feliz: la naturaleza humana es para el hombre toda su posibilidad, pero también todo su límite y su único límite. Sin embargo, cuando desde la concepción ética de la moral se proponen teorías y se discute de normas y valores, a penas se habla del hombre. Hablar de moral no es ocuparse de la sociedad sin más, de promover vínculos sociales de convivencia y de comunicación; de consolidar y dinamizar una democracia mediante la capacidad de diálogo, la justicia, la solidaridad, la tolerancia o los derechos humanos. Por supuesto que la moral, la concepción humana de la moral, ha de ocuparse y hablar de la sociedad, de la democracia, de la justicia y de los derechos humanos, pero no desde una concepción sociológica de la solidaridad y de la tolerancia, no desde una concepción política de la democracia, ni desde una concepción jurídica de los derechos humanos, sino desde una concepción antropológica que los considera como factores, condiciones o contenidos de la autorrealización interpersonal, desde una concepción del hombre que es el fundamento, principio y fin de la democracia y de los derechos humanos. Y al pensar desde y para el hombre la democracia o los derechos, aparecen a veces los mismos términos pero como conceptos diferentes y, por lo tanto, con implicaciones prácticas y transformadoras más profundas, más radicales y más comprometidas.

\subsection{Teorías éticas o moralistas de la educación moral. Crítica humana}

Claro está que desde esta perspectiva saben a poco las propuestas de los modelos psicopedagógicos clásicos, no parecen asumibles tal cual se formulan, ni están bien fundadas porque son propuestas educativas pensadas desde una u otra concepción autorreferencial o ética de la moral en la que se basan. 
Desde la filosofía moral, J. Rubio Carracedo entiende que «la educación moral ha de conducir a la madurez moral o moral adulta, que se expresa en la autonomía moral de los sujetos superando todas formas, directas e indirectas, de heteronomía», y que su finalidad es "capacitar a las personas para resolver de modo responsable y autónomo las alternativas o conflictos axiológicos que se le presentan» $y$, en este sentido, la educación moral es tarea de construcción dialógica de ciertas normas y pautas de conducta superando así la mera socialización adaptativa y el mero individualismo subjetivista ${ }^{21}$. De manera análoga, según E. Guisán, la ética «nos enseña a transitar de la moralidad positiva a la moralidad crítica, o lo que es igual, de la moral que nos imponen los agentes socializadores a una nueva moral que diseñamos en diálogo intersubjetivo que la actividad filosófica propicia», enfrentándose a la doxa para recabar fidelidad a la veracidad y autenticidad de los individuos; por lo tanto «el reto con el que ha de enfrentarse la filosofía moral, y por añadidura la educación moral contemporánea, es el de superar a un tiempo el relativismo y el objetivismo dogmático en ética, no admitiendo ni el «todo vale» ni la proclamación de valores aprióricos por encima de los intereses humanos». Por otra parte, se trata también de ir más allá del egocentrismo complementando la educación de las capacidades críticas de los sujetos mediante la insistencia, por ejemplo, en la «ampliación de los sentimientos de sympatheia», así como en la «sensibilización frente a los problemas sociales y de los individuos en particular, como individuos» $»^{22}$. Los objetivos de la educación moral según M. Vidal se reducen a uno sólo: «lograr que el individuo humano adquiera la madurez moral por medio de la evolución armónica y el desarrollo justo de su potencial ético»; es decir, se trata de lograr el desarrollo moral en todos sus aspectos: coherencia personal, consecución del nivel de los principios morales autoaceptados críticamente, prevalencia de las actitudes morales de madurez tales como racionalidad, altruismo, etc., paso del respeto unilateral —heteronomía - a la reciprocidad - autonomía-, así como impulso de los factores cognitivos, afectivos y motivacionales que integran la realidad moral ${ }^{23}$. Más próxima a una concepción moral de la moral, para A. Cortina educar moralmente significa «ayudar a sentirse en forma, ayudar a ilusionarse con los propios proyectos de autorrealización,

${ }^{21}$ J. Rubio CarraCEDO, op. cit., pp. 11 y 65, respectivamente. Asimismo El hombre y la ética, Anthropos, Barcelona, 1987.

${ }^{22}$ E. GUISÁN, op. cit., pp. 87, 94 y 95, respectivamente.

${ }^{23}$ M. VIDAL, La estimativa moral. Propuestas para la educación ética, Madrid, PPC, 1996, pp. 102 y 114 , respectivamente. 
desde la conciencia de que es posible llevarlos a cabo» porque frente al egoísmo y altruismo extremos está el quicio de la autoestima; y por otra parte «es imprescindible educar para la felicidad», pero también «ayudar a desarrollar la capacidad para experimentar placer, de lo que en la realidad es sensiblemente valioso» ${ }^{24}$.

Vimos antes varias referencias a la psicopedagogía moral; pues bien, me interesa resaltar algunas de ellas y mencionar tan sólo otras que también contienen elementos nuevos. Es, por ejemplo, la teoría de J. M. a Puig Rovira que entiende la educación moral como construcción de la personalidad moral. La moral no es algo dado de antemano, presupuesto o que simplemente se decide o elige, sino que la moral es «un producto cultural cuya creación depende de cada sujeto y del conjunto de todos ellos»; consecuentemente, la educación moral como construcción «reconoce el momento o el contenido socializador que siempre tiene la educación moral, pero considera imprescindible subrayar la vertiente crítica, creativa y autónoma de la moralidad » 2 . Puig Rovira y Martín García definen la educación en un sentido amplio como «socialización», pero en un sentido estricto destacan en ella "una vertiente creativa, crítica y transformadora» ${ }^{26}$. Por lo tanto, la educación moral pretende que los alumnos: a) desarrollen su inteligencia moral; b) adquieran la cultura moral necesaria para enfrentarse dialógica y autónomamente a las situaciones que suponen un conflicto de valores, de forma que c) les sea posible vivir de modo justo, solidario y feliz.

R. S. Peters, por su parte, entiende que la educación moral «trata de lograr que las personas se realicen dentro de actividades consideradas valiosas, en una forma que involucra un entendimiento dotado de cierta clase de profundidad y alcance». Implica, por lo tanto, que la educación se relaciona en gran medida con la «interiorización» en ellos de lo que es valioso para seguirlo y apreciarlo por sí mismo y no por sus posibles resultados, pero implica también que la educación debe involucrar conocimiento y entendimiento porque, además, también se necesitan principios, y algunos principios son más justificables que otros ${ }^{27}$. Peters,

${ }^{24}$ A. CORTina, El quehacer ético. Guía para la educación moral, op. cit., pp. 102 y 114, respectivamente

${ }^{25}$ J. M. a PUIG Rovira, op. cit., pp. 66 y 67, respectivamente.

${ }^{26}$ J. M. a Puig Rovira y X. MARTín García, La educación moral en la escuela, Edebé, Barcelona, 1998, pp. 17 y 23, y 25 los dos últimos textos.

${ }^{27}$ R. S. Peters, op. cit., p. 56. Cfr. F. BÁrCena y J. C. Mólich, La educación como acontecimiento ético, Paidós, Barcelona, 2000. 
como vimos antes, quiere compatibilizar una línea centrada en la formación de hábitos, en la tradición, etc. y la línea del desarrollo del pensamiento y elección crítica; pero siendo complementarios, insiste más en los hábitos que en el pensamiento. Aportaciones en esta línea general son las investigaciones de M. L. Hoffman, C. Freinet o J. M. ${ }^{\text {a }}$ Quintana ${ }^{28}$.

Otros estudios contienen un elemento sociopolítico importante. En J. Piaget «Los procedimientos de la educación moral», ya encontramos la idea de que «el fin de la educación moral es el crear personalidades autónomas aptas para la cooperación» ${ }^{29}$. C. Borrego de Dios propone una educación moral para el «desarrollo de hábitos y competencias sociales, en cuanto facilita la integración del grupo e impulsa una comunidad que facilite los vínculos afectivos y las relaciones de pertenencia, para promover en los niños su integración en grupos en los que su desarrollo sociopersonal y moral se vea facilitado ${ }^{30}$. Por otra parte, escribía V. Camps que educar es «formar el carácter para que se cumpla un proceso de socialización imprescindible, y formarlo para promover un mundo más civilizado, crítico con los defectos del presente y comprometido con el proceso moral de las estructuras y actitudes sociales», lo cual requiere inculcar valores sencillamente humanos recuperando el valor de la humanidad. Y ya en Virtudes públicas había dicho que «la función de la ética es enseñar a querer lo que merece ser querido, educar los sentimientos para que se adhieran a los fines que promuevan la justicia»; hay que reconstruir la moral como un conjunto de virtudes: «una ética de actitudes e inclinaciones individuales dirigida a hacer más justa y digna la vida colectiva», porque entiende la moral como el conjunto de virtudes o «la serie de cualidades que deberían poseer los seres humanos para serlo de veras y para formar sociedades igualmente humanas» ${ }^{31}$. Según M. ${ }^{a}$ Rosa Buxarrais «los motivos que impulsan a plantearse la educación moral pueden sintetizarse en la necesidad de apreciar, mantener y profundizar en la democracia, así como de

${ }^{28}$ M. L. HoffMAN, «Empty, social cognition and moral action», en HofFMAN, KURTIUS y GEVIRTZ, Handbook of moral behavior and development, v. 1, New York, Hillsdale, LEA, 1991, pp. 275-301. C. FreInET, La educación moral y civica, Laia, Barcelona, 1972. J. M. ${ }^{\text {a QUINTANA, Teo- }}$ ría de la educación, Dykinson, Madrid, 1988. Id., Pedagogía moral, Dykinson, Madrid, 1995.

${ }^{29}$ J. PiageT en VV.AA., La nueva educación moral, Buenos Aires, 1967, p. 19.

30 C. BORREGO DE Dios, «Desarrollo socio-personal y moral: la cara interna de la educación global», en Investigar en la escuela, 37, 1999, pp. 85-98, p. 93.

${ }^{31}$ V. CAMPS, Los valores de la educación, Alauda, Madrid, 1993, p. 11, y Virtudes públicas, Espasa Calpe, Madrid, 1995, pp. 9-10, 11 y 17, respectivamente. 
incorporarla a los propios hábitos personales de interrelación»; aquí ha de estar incluida la idea de que «la educación moral pretende colaborar con los jóvenes para facilitarles el desarrollo y la formación de todas aquellas capacidades que intervienen en el juicio y en la acción moral, a fin de que sean capaces de orientarse de modo racional y autónomo en aquellas situaciones que les plantean un conflicto de valores», pero dentro de un modelo de educación moral que parte de los principios de autonomía y razón dialógica que posibilitan la crítica, el respeto a los derechos humanos y la apertura a los demás, y puede «ayudarnos a vivir una vida más justa y solidaria ${ }^{32}$. En su teoría sobre la educación, Amy Guttman considera que todo proyecto educativo es en sí un proyecto político: educar es formar ciudadanos para una sociedad; por eso defiende un modelo socioeducativo que ella denomina «estado democrático de la educación», entendiendo que el Estado tiene derecho a transmitir la escala de valores de la sociedad democrática para la integración de todos los individuos en la sociedad plural y tolerante, que es el objetivo de toda educación ${ }^{33}$.

Asimismo, dentro de esta línea de relaciones intersubjetivas, P. Ortega y R. Mínguez piensan en la necesidad de educar en aquellas competencias morales y cívicas indispensables al ciudadano para lograr una sociedad justa y pacífica, y un planeta a la medida del hombre y respetuoso con la vida: competencia moral para el diálogo y convivencia entre los pueblos e individuos de distintas culturas; competencia para la acción responsable contra la desigualdad y exclusión de los pueblos del Sur, y competencia para establecer relaciones respetuosas con el medio natural y urbano. Estos tres ámbitos son los principales retos del hombre de hoy en la mayor parte del planeta y los problemas más básicos que vertebran nuestra vida moral más que ningún otro. La referencia a los demás es fundamental: la educación moral es «educar en y para la responsabilidad ... frente a los demás», desarrollar la capacidad de pensar y actuar autónomamente desde los parámetros de «justicia y equidad», y de ponerse en el lugar del otro. Aquí está su inspiración en E. Lévinas: educar moralmente es "preparar al individuo para mirar al rostro del otro, desde la responsabilidad y la compasión", porque en el acontecimiento del encuentro con el otro nace la ética como respuesta a la deman-

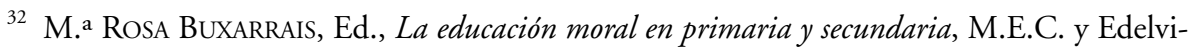
ves, Madrid, 1995, p. 16 los dos primeros textos, y p. 21.

33 GutTMan, A., La educación democrática. Una teoría política de la educación, Paidós, Barcelona, 2001. 
da de acogida y ayuda del otro hombre. Educar moralmente es educar «para responder no sólo al otro, sino del otro, hacerse cargo de él» porque el otro con su sola presencia me hace responsable de él. La promoción y defensa de los intereses de la comunidad es un deber para todos sus miembros, por eso se habla de una ciudadanía de «alta intensidad» o maximalista que requiere al individuo desde el horizonte amplio de los derechos humanos implicándose activamente en su realización ${ }^{34}$.

Desde la concepción y fundamentación antropológica de la moral, desde una concepción humana de la moral, esas teorías parecen un tanto parciales en cuanto parcelan o recortan el ámbito de la educación moral, o porque de una manera u otra implican la visión de un hombre reducido, una visión parcial que no contempla al hombre en su unidad y totalidad, y en su autorrealización. Partiendo de una concepción ética de la moral, esas investigaciones psicopedagógicas se adhieren a una filosofía moral dada, generalmente de forma más implícita que críticamente asumida, y en función de este sistema ético construyen una teoría del desarrollo moral, de la persona moral, etc. que termina con la propuesta consecuente de una concepción de la educación moral. Dos ejemplos muy elocuentes son los siguientes. J. M. ${ }^{a}$ Quintanta, al hablar de la educación moral, la primera cuestión común que se plantea es "¿qué educación moral vamos a dar? Es decir, ¿qué moral vamos a proponer? ... Esto significa que el educador ha de adoptar un sistema ético correcto que es el que le definirá las normas morales» ${ }^{35}$. También M. Vidal es bien claro al respecto: «la educación moral en el sistema educativo ha de ser formulada desde y para la ética civil. Ello supone optar por el contenido propiciado por la ética asumida por la sociedad pluralista y democrática en su conjunto» ${ }^{36}$. Concepciones como éstas habrán tenido en cuenta las distintas corrientes filosóficas y las teorías sociológicas y políticas que les hayan parecido pertinentes en un momento u otro de su proceso investigador, pero en

${ }^{34}$ P. ORTega y R. Mínguez, La educación moral del ciudadano de hoy, Paidós, Barcelona, 2001, pp. 22-24, y E. LÉVINAS, Le temps et l'autre, P.U.F., Paris, 1991; De l'existence à l'existent, Vrin, Paris, 1993; Humanisme de l'autre homme, Fata Morgura, 1972. Para el último aspecto aludido cfr. C. NAVAL, Educar ciudadanos. La polémica liberal-comunitarista en educación, EUNSA, Pamplona, 1995.

35 J. M. ${ }^{a}$ QUINTANa, Teoría de la educación, op. cit., p. 292; asimismo Pedagogía moral y Pedagogía axiológica, ambos en Dykinson, Madrid, 1998 y 1995, respectivamente.

${ }^{36}$ M. VIDAL, La estimativa moral. Propuestas para la educación ética, PPC, Madrid, 1996, p. 148. 
ningún momento se han ocupado temáticamente del ser humano, que es principio y fin de la investigación moral y, en consecuencia, de toda propuesta de educación moral. Más razonable e imprescindible es, inversamente, comenzar por conocer y comprender a los seres humanos, la naturaleza humana de los individuos, para entender qué ha de ser la moral — si es que ha de ser algo- y concluir consecuentemente en una teoría humana de la moral, del desarrollo moral y de la educación moral.

No quiero decir, sin embargo, que sean erróneas las propuestas educativas aludidas: todas son igualmente válidas, pero solamente lo son en cuanto apuntan a aspectos concretos relativos a distintas dimensiones de la autorrealización humana de los individuos. Por lo tanto, y en este sentido, la educación es todo eso que sus autores proponen, pero lo es secundaria y derivadamente, y por eso a todas esas teorías les falta al menos el principio primero y el último porqué, la última razón que proporcionaría una base totalmente sólida a sus proyectos educativos y a sus propuestas y contenidos concretos; porque la moral moralista o autorreferencial, la moral concebida éticamente, no se justifica por sí misma y tampoco la educación moral que se basa en ella. Dicho de otra manera: las concepciones éticas y socio-educativas aludidas, en cuanto no suponen una concepción humana de la moral, carecen de fundamento último, de fuerza moral, de capacidad de convicción y de razón suficiente para mover como ideal práctico a la acción y conducta consecuentes con los objetivos que proponen a quien se encierra en su egocentrismo, en sus intereses creados, en el placer de lo inmediato o de lo superficial y material, etc.; sólo estimulan a quien ya ha asumido previamente tales valores y objetivos.

No es difícil reconocer algo que es de suyo evidente: de la misma manera que la sociología y la moral son distintas e irreductibles, aunque tienen configurado un espacio común, así también y por eso mismo los problemas sociales son problemas sociales y no problemas morales. Consecuentemente, los problemas sociales se caracterizan por rasgos peculiares que difieren de los rasgos que caracterizan peculiarmente a los problemas morales $\mathrm{y}$, además, los problemas sociales requieren soluciones sociales mientras que los problemas morales hay que resolverlos moralmente. Ocurre, no obstante, con frecuencia que muchos problemas sociales encierran y son también problemas morales, y a la inversa; pero siguen siendo problemas específicamente y no vale confundirlos; no vale señalar un problema social para constatar un problema moral, ni vale aducir razones y objeti- 
vos sociales para crear un obligación moral y estimular una respuesta moral. Pero es el hecho de que con mucha frecuencia los textos que leemos nos presentan problemas sociales dando por supuesto que se trata, por eso mismo, de problemas morales, porque no ven el contenido propiamente moral que puede haber en esos problemas, ni conciben entonces verdaderas razones morales para las acciones que los individuos han de realizar para resolverlos.

Por ejemplo, la educación verdaderamente moral no debería orientarse hacia el bienestar, sino más bien hacia la autorrealización interpersonal y la felicidad; y por lo tanto también hacia el bienestar, pero en función de la autorrealización y de la felicidad. Pero entonces no sólo debería orientarse hacia el bienestar, sino también hacia otros contenidos y dimensiones de la felicidad cuya realización podría interferir el bienestar mismo en la medida en que el bienestar nunca es fin último incondicionado.

Otro ejemplo: las concepciones expuestas proponen programas de educación moral que la orientan hacia distintos objetivos muy determinados, pero no dejan percibir la moralidad con la que sus autores pretendían caracterizarlos, ni las razones morales de fondo para que deban ser asumidos; solamente llega a percibirse en ellos los tópicos ético-morales comúnmente admitidos que parecen constituir un fundamento sólido, pero que en sí mismos no se justifican moralmente ni tienen su razón moral de ser; tan sólo constituyen razones y objetivos meramente sociopolíticos, sociojurídicos, etc. en cuanto no se ve en la argumentación que los sostiene una referencia al contenido y fundamento antropológico que habría de caracterizarlos como morales: ¿por qué debe moralmente una persona asumir prácticamente para y en su propia vida el altruismo, la solidaridad, la justicia o determinada forma de convivencia, etc. como proponen las concepciones conocidas de la educación moral?, ¿por qué tendría uno que mirar el rostro del otro sintiéndose interpelado por él, y por qué su llamada habría de ser un mandato inapelable, y el servicio que le da sería algo debido: por qué asumir esta responsabilidad frente al otro?, ¿por qué razón uno ha de promover y participar en las soluciones para el bien social y el interés de la comunidad, así como en su hospitalidad? ${ }^{37}$, ¿por qué razón hay que educar el carácter y la coherencia personal, como proponen los educadores morales, por

37 Cfr. D. Innerarity, Ética de la hospitalidad, Península, Barcelona, 2001. 
qué su empeño en educar en los valores y en las virtudes y por qué ser virtuoso: por qué, para qué, por quién; es decir, quién los define, los impone y los exige?, ¿por qué educar la capacidad del juicio moral, del discurso dialógico y la autonomía del sujeto, y por qué habría que seguir unas ideas pedagógicas que estudian el desarrollo moral culturalmente, como proceso de socialización, o desde un enfoque ecológico, el life-span, etc.? ${ }^{38}$, ¿por qué el individuo ha de asumir que la justicia, la solidaridad y la autonomía constituyen el verdadero paradigma moral, imprescindible, por otra parte, para que la sociedad funcione y necesario sociopolíticamente: por qué ha de ser un principio que se le viene encima al sujeto, exigido por la sociedad democrática misma?, y en esta línea ¿por qué asumir la democracia como procedimiento moral para solucionar los conflictos de valores morales?, ¿por qué la educación moral ha de transmitir el modelo de la ética civil vigente en una sociedad democrática, considerando como objeto de la moral mantener y consolidar el pluralismo y la democracia, cuando esta misma democracia esencialmente plural no puede justificarse por sí misma? No por meras razones sociológicas, políticas, jurídicas o pedagógicas, sino solamente en razón de que en tales casos está directamente comprometido el ser humano como tal y su plenitud compartida y convivida; es decir, únicamente por razones morales. Las cuestiones sociales y políticas contenidas en las propuestas educativas que ya conocemos plantean también verdaderos problemas morales y constituyen objetivos morales pensados normativamente; pero no es su carácter social o político lo que obliga moralmente al individuo interpelado por ellos. Obliga su moralidad, el problema humano de autorrealización individual y necesariamente recíproca. Por lo tanto, hay moralmente que afirmar y promover los derechos humanos, por ejemplo, pero no por meras razones de ciudadanía, o de conveniencia política o de justicia jurídica, sino por una exigencia profunda y esencialmente humana y moral. No obstante, la realización de los derechos humanos tiene necesariamente dimensiones y exigencias sociopolíticas y jurídicas amplias, profundas e ineludibles; por eso, vale también un planteamiento estrictamente social y político de los derechos humanos, pero sólo serán razones morales las que se puedan invocar para comprometer a los ciudadanos en su realización.

${ }^{38}$ Merece atención en este punto el estudio y las amplias referencias que aporta la profesora M. P. AlejANDRA CORTÉs PASCUAL en su libro Hacia un modelo de comprensión del desarrollo moral desde Kohlberg y Bronfenbrenner. Un estudio comparativo e intergeneracional, Universidad del País Vasco, San Sebastián, 2001. 
De otra manera no hay razón suficiente para educar según unas u otras de esas propuestas psicopedgógicas, para asumir esos criterios, principios y objetivos, ni para que una persona condicione tanto su propia vida y la limite con todos esos compromisos en vez de vivir como quiera vivir dentro de las reglas de juego sociales y jurídicas, es decir, en tanto no interfiera injustamente en el querer ser y vivir de los otros. La respuesta sólo puede venir de una concepción humana de la moral que contempla al hombre, al ser humano, y lo ve natural e intrínsecamente comprometido tanto y tan ineludiblemente consigo mismo como con los demás: no tengo que mirar al otro porque tengo mirar al otro, ni hay que cultivar la convivencia democrática porque hay que cultivar la convivencia democrática, etc. en beneficio de la sociedad o de alguna otra entidad suprema. Nada ni nadie puede obligar moralmente a una persona: ni la simpatía ni la justicia, ni la sociedad ni la democracia, etc. a no ser que tenga una dimensión moral constitutiva bien definida y fundada, en razón de la cual el individuo se sepa y se sienta apelado y comprometido como ser humano en un proyecto de autorrealización recíproca. Toda heteronomía moral encierra una contradictio in terminis y es infundada: la norma, la obligación y lo debido moralmente no puede serle impuesto y exigido al ser humano, a ninguna persona, a priori de él mismo, desde fuera de sí, sino que es interna al individuo mismo y surge de su propia naturaleza humana; es la manera de ser y de lograr su plenitud humana.

\subsection{Educación moral}

La insuficiencia de las anteriores concepciones psicopedagógicas relativa a las metas de la educación moral, a las condiciones y rasgos del desarrollo moral como desarrollo humano íntegro, insuficientes porque están pensadas desde una concepción moralista o social de la moral, me lleva a exponer en positivo una concepción de la educación moral tal como se deriva de su concepción y fundamentación antropológica entendida desde la concepción humana de la moral. Ahora sólo puedo definirla y concretarla en las características y condiciones mínimas que ha de cumplir como educación moral. Pero importa tener muy en cuenta que la educación moral, ciertamente, ha de conocer y enseñar las teorías, los problemas y los conceptos históricos de la moral y las circunstancias que actualmente determinan la vida de los hombres, pero sobre todo ha de descubrir la raíz de esos problemas, el sentido y el significado más originario y más profundamente humano de la moral y se ha de ocupar del hecho moral más radical: la 
moralidad de la naturaleza humana o el hombre moral por naturaleza. La educación moral tiene, efectivamente, una dimensión formativa integral del sujeto y de sus capacidades, pero se ocupa ante todo de la persona, del ser humano en su integridad, en la integridad de su unidad y totalidad. Me refiero aquí, por lo tanto, no a una teoría integral de la educación moral, del desarrollo humano y moral del sujeto, sino a la idea de una educación moral para el desarrollo íntegro del individuo como ser humano y según su naturaleza humana.

Continuando lo que decía en otro momento, entiendo que la moral es autorrealización personal y humana, plena, unitaria y vinculada y vinculante con la autorrealización del otro, de los otros, y por lo tanto correalizada y vivida como felicidad compartida, en y mediante la vida que vivimos, en la vida cotidiana de cada uno en toda su riqueza y en todos sus contenidos, desarrollando todas sus dimensiones naturales incluso aquellas que apenas cultivamos y que casi ignoramos empobreciendo nuestra vida y a nosotros mismos; pero también en toda su complejidad, en la abundancia de sus requerimientos, necesidades, deseos, problemas y esfuerzos compartidos y discutidos en una tupida red de relaciones interpersonales próximas y distantes, agradables y problemáticas en muchos sentidos; y sabemos que toda esta realización personal está impregnada de connotaciones psicológicas, sociales, políticas y culturales. Esto es la moral y, en consecuencia, en esto consiste la educación moral y a ello debe orientarse como su objetivo primero y último, así como a todos los factores racionales, afectivos y motivacionales que lo condicionan, posibilitan y favorecen: debe ser orientación, guía, estímulo, ayuda y formación para la autorrealización correalizada, para el desarrollo íntegro del ser humano en su unidad y totalidad en la vida rica y compleja, cotidiana, de cada uno mediada desde dentro o hecha intrínsecamente por los demás en mayor o menor medida. Para todo ello bueno es conocer, desarrollar y contar con recursos y contenidos específicamente morales como valores, virtudes, actitudes, normas, etc. los cuales ayudan a llevar a cabo esta tarea moral de la autorrealización interpersonal. Por lo tanto, ellos han de ser, asimismo, contenidos de una educación moral bien definida y programada, consciente de y consecuente con su contenido y finalidad específica y apoyada en estrategias como los dilemas morales, las enseñanzas transversales, los ejercicios de autoestima, la cooperación y la construcción conceptual, etc.

Todo esto se da y ocurre habitualmente de una manera u otra en la vida cotidiana; por eso, en definitiva, la moral y la educación moral tratan de hacer rea- 
lidad querida y opción y proyecto deliberado lo que frecuentemente es ya de hecho realidad involuntaria y espontánea y producto reflejo de la mera interacción social y personal. Todo contenido de la educación moral educativo va orientado a un sujeto que trata de realizar día a día la plenitud de su naturaleza humana y la felicidad vivencialmente compartida, a impulsar este élan vital de plena autorrealización. La educación moral es enseñar al individuo a vivir según su naturaleza humana y moral, como realización de todas sus potencialidades en la unidad de su ser, del yo que cada uno es.

La educación moral es educación para el desarrollo de la personalidad humana y moral; educación para la felicidad antes y más que educación para el bienestar, pero para la felicidad entendida ante todo no como logro de nuestras metas y fines propuestos, sino como vivencia de la autorrealización, y por eso es también educación para el bienestar y capacitación para lograr nuestros fines y metas porque el bienestar y la satisfacción de nuestras aspiraciones y deseos condicionan y son contenidos, de alguna manera, de la felicidad. La educación moral es educación para la solidaridad; lo cual quiere decir, negativamente, que podrá la educación moral incluir la educación para la simpatía y la justicia como también se ha dicho con frecuencia, pero ni la simpatía ni la justicia son objetivo primero e inmediato de la educación moral; porque tampoco son manifestación moral originaria de la naturaleza humana; es decir, no son propiamente y por lo tanto virtudes morales, y sólo concomitantemente han de ser objeto de la educación moral.

La simpatía es un sentimiento espontáneo del individuo, como otros sentimientos y como otras reacciones inmediatas a determinadas cosas, hechos o personas que nos estimulan: más bien se trata de educar la manera de responder prácticamente el individuo, en la vivencia de la simpatía así como en la vivencia de la antipatía, para que las respuestas puntuales y la manera como habitualmente responde sea moral y virtuosa. Más que educar en la simpatía hay que formar y cultivar las actitudes básicas positivas respecto a nosotros y respecto a los demás en nuestra relación y comunicación con ellos, porque esta relación y comunicación no puede ser mero resultado o reacción de simpatía o de antipatía; pero las actitudes no son sentimientos y reacciones espontáneas como la simpatía y la antipatía y está en nuestras manos estimularlas y moldearlas mediante la educación.

La justicia, por su parte, ha sido una virtud moral, y una virtud básica desde los filósofos griegos, sólo porque nunca se ha pensado el contenido profun- 
damente humano y radicalmente moral de la solidaridad, consistentes en la dimensión transcendente y de correalización de la naturaleza humana del hombre, algo bastante más serio, responsable y comprometido que la mera compasión y la adhesión a determinadas causas. No se entienden ni se justifican las llamadas a la justicia para apoyar una obligación ineludible respecto a otros, no pasarían éstas de ser obligaciones de justicia sin fundamento moral alguno, si no fuera porque son en el fondo llamadas a la solidaridad humana, si no fuera porque en realidad se trata de verdaderas exigencias de solidaridad moral. Y la justicia, en cambio, sólo constituye una auténtica obligación cuando tiene un fundamento jurídico; pero entonces ya no es obligación moral, ni se trata de la justicia como virtud moral. Ciertamente, hay muchas ocasiones en las que pensamos, independientemente del derecho, que hay que obrar de una manera determinada, que hay que hacer algo, por razones de justicia: decimos que una situación no es justa y que no es justo que ocurra tal discriminación, tales abusos, etc. y efectivamente lo decimos con cierta razón. Pues bien, en tales situaciones entiendo que algo «no es justo» puede significar que «no hay derecho», que «no está bien» que ocurra tal cosa, pero en el fondo y sobre todo significa que no es de hecho el ordenamiento jurídico sino la naturaleza humana la que no permite, la que no da "derecho» a esas injusticias, y que es en razón de la naturaleza humana de las personas, de la humanidad de los hombres por la que no se deben dar ni consentir que sigan dándose esas situaciones inhumanas, inmorales e insolidarias más y antes que injustas, y que por eso mismo no deberían ser justas, aunque podrían serlo si no infringen derecho alguno. Hay que entender antropológica y moralmente la solidaridad en su sentido radicalmente humano: como manera de ser la naturaleza humana y elemento constitutivo del ser humano, de las personas concretas que somos; como transcendencia humana recíproca a todos los individuos que se concreta necesariamente como correalización interpersonal. La solidaridad es más radical y la razón y el fundamento de la justicia y no, como se entiende desde una concepción ética o autorreferencial de la moral, una exigencia moral complementaria para la acción y las situaciones a las que no puede llegar la justicia. La justicia, muchas veces confundida con una verdadera solidaridad no percibida como tal, y otras muchas como verdadera categoría jurídica, siempre ha tendido a resolver las desigualdades entre los hombres provocadas, en su caso, por la fuerza, el conocimiento, la astucia o la maldad de unos frente a la debilidad, ignorancia, buena fe o ingenuidad y la bondad de otros cuando esta desigualdad lesiona de manera evidente a los desprotegidos. La justicia restituye un equilibrio, protege la igualdad efectiva de derechos. Este es también su 
límite: ir más allá de esta restitución y de esa protección es ir más allá de la justicia y ninguna otra norma o deber constituye una obligación de justicia.

Se trata, por lo tanto, de educar para la solidaridad, pero también de cultivar un sentido de la justicia que lleve a asumirla con la mayor espontaneidad. Es necesario pensar y programar una educación moral que promocione una cultura moral de la solidaridad correalizante entre los hombres antes que priorizar las relaciones de justicia entre los ciudadanos, porque si hubiera solidaridad no sería necesaria la justicia.

La educación moral es verdaderamente todo eso que han propuesto las distintas teorías, pero lo es solamente en función de su referencia inmediata al hombre, lo es si y en cuanto tales propuestas son constitutivas del desarrollo humano y personal del individuo, como contenido y condición para la plenitud humana. De ahí que el modelo antropológico de la educación moral en el que pienso no es en absoluto incompatible con esas teorías, sino que de alguna manera recoge y fundamenta sus propuestas porque la idea de que la educación moral se orienta al desarrollo integral de la persona, a su plenitud posible como ser humano, ha de traducirse en propuestas materiales concretas como los contenidos de las concepciones anteriores, pero entendidos desde un punto de vista auténticamente moral, incorporándolos como verdaderos contenidos antropológicos de la moral. Si no se percibe y se aprecia la realidad que fundamenta, requiere y lleva necesariamente a una concepción humana de la moral y se limita uno a la realidad de la teoría y de los conceptos morales, y a la realidad sociopolítica en la cual y en cuya referencia tienen lugar los debates filosóficos y psicopedagógicos, la exigencia con la que de esta manera se requiere a los hombres como seres humanos y como ciudadanos a cumplir con los deberes que se les proponen, carece de razones convincentes y suficientemente sólidas para que el individuo se reconozca y se sienta obligado moralmente con tales propuestas: desde una concepción moralista o sociopolítica de la moral y de la educación moral ¿cómo podríamos conocer y proponer hasta dónde, hasta qué aspectos y contenidos personales, sociales y políticos llegan las exigencias morales de deber y de compromiso y de transformación personal y sociopolítica, e incluso cómo determinar un mínimo moral aceptable?. Sólo la concepción y fundamentación antropológica de la moral, sólo la concepción humana de la moral, en cuanto tiene como referencia inmediata única el ser humano mismo y su proyecto de plena autorrealización y no otras teorías ni otras realidades, puede proponer un ideal moral de vida indivi- 
dual y de transformación moral de la vida social y política, y un modelo de educación moral consecuente con ese ideal de perfección.

Finalmente, la educación moral se orienta a la transformación radical y decidida de la sociedad individualista actual en una auténtica comunidad humana, y a una profunda democratización de la democracia. Hemos oído ya muchas veces que buena parte de los grandes problemas que sufren muchos hombres de hoy y que preocupan a la humanidad actual tienen una fácil solución científica y técnica, pero requieren sobre todo una difícil capacidad moral para resolver$\operatorname{los}^{39}$. La sociedad actual, sobre todo en sus esferas de poder creciente, y debido quizá a la mentalidad utilitarista y a la racionalidad instrumental predominante, plantea y busca las soluciones científicas y técnicas a los grandes problemas, aplicables, frecuentemente, sólo en la medida en que no interfieran intereses políticos, económicos, personales, de partido o de grupos de presión. Estos problemas y estos vacíos de poder hacen bien patente que las soluciones científicas y técnicas, de suyo, sólo pueden resolver problemas científicos y técnicos, pero son insuficientes y estériles para los problemas verdaderamente morales de nuestra sociedad y de la humanidad actual: los verdaderos problemas morales y humanos se resuelven moralmente, primera y necesariamente, o no se resuelven. Lo cual significa primero tomar conciencia de ellos, percibirlos, y no sólo tomar en serio los derechos y las aspiraciones más humanamente legítimas, el sufrimiento de la humanidad doliente, la indignidad que hunde y anula a muchos hombres y mujeres, sino implicarse en ellos, plantearlos críticamente y, en cuanto la respuesta humana y moral lo requiera, acudir entonces sin condiciones a los recursos científicos, técnicos y económicos necesarios. Los problemas humanos y morales de fondo en nuestra sociedad no son problemas técnicos, ni se detienen en

${ }^{39}$ M. a ROSA BUXARRAIS, por ejemplo, entiende que un motivo para preocuparse por la educación moral es que hoy los problemas más importantes para la humanidad no son los que tienen una solución exclusivamente científico-técnica, sino que son situaciones que reclaman una reorientación ética de los principios que los regulan; op. cit., pp. 15-16. Casi con las mismas palabras J. M. ${ }^{a}$ Puig Rovira y M. Martínez expresan esta idea diciendo que la educación moral es necesaria porque los mayores problemas de la humanidad en conjunto no tienen en lo fundamental una solución técnico-científica sino que precisan de una reorientación ética de los principios que regulan las relaciones entre los hombres y las relaciones de éstos con su entorno natural; op. cit., p. 14. Estos problemas son, por ejemplo, los que centran hoy mismo la atención en la Cumbre de la O.N.U., Johanesburgo — 26 de Agosto a 4 de Septiembre, 2002—: los problemas Norte-Sur, el desarrollo sostenible, etc. 
ellos la ciencia o la economía, pero sí son también problemas sociales y políticos que no pueden ser soslayados ni estar condicionados o sometidos a ninguna necesidad distinta de las exigencias de la naturaleza humana. Tales problemas requieren un replanteamiento moral de la sociedad, de la política y del derecho, que capte los problemas humanos subyacentes a los problemas y las injusticias sociales y adopte soluciones eficaces y definitivas que los resuelvan.

Ahora bien, esta reconsideración que prioriza el problema de la dignidad humana y requiere inmediata solución mediante todos los recursos necesarios, parece tan utópica, pero a la vez tan imprescindible y urgente, como la consecuencia moralmente revolucionaria que implica: la necesidad humana de revisar la sociedad actual, sus estructuras, instituciones y conciencia cultural, su propia organización política y jurídica con la exigencia de transformación a fondo, radical, pausada pero continua, de la sociedad meramente social de relaciones individuales extrínsecas a las personas mismas, de intereses creados de hombres enfrentados en una competencia alienante en la realización sociocultural de sus potencialidades humanas, en una auténtica comunidad humana de hombres y mujeres en relaciones de autorrealización correalizada y recíproca hacia su plenitud como seres humanos. Es necesario moralizar y humanizar la sociedad y la convivencia social, la vida privada y la vida pública: es necesario comunitarizar la sociedad, y moralizar o democratizar la democracia.

Todo ello conlleva, significa y requiere para que sea posible - y éste es, desde otra perspectiva, el objetivo de la educación moral — una transmutación no tanto de los valores proclamados como de la escala efectiva de valores; una transmutación por lo tanto y sobre todo de los hábitos mentales y volitivos, de la capacidad de decisión, porque, por decirlo de alguna manera, el mundo camina todavía cabeza abajo y es necesario ponerlo del todo sobre sus pies. La educación moral ha de orientarse hacia la coherencia de la conducta y las opciones decididas por el individuo con los criterios asumidos, con los derechos humanos proclamados, con la dignidad humana exigida y con la concepción del hombre que públicamente se predica.

Resumiendo las ideas expuestas, y según la concepción humana de la moral y de la educación moral, diría que ésta se orienta a lograr la plena autorrealización del sujeto correalizada recíprocamente por los demás, al desarrollo interpersonal íntegro de los individuos como seres humanos en su unidad y totalidad 
y a la capacidad para vivir una vida de felicidad; y por lo tanto, se orienta también a comunitarizar la sociedad y democratizar la democracia, y a tomar conciencia de los problemas humanos y morales de fondo presentes en la problemas actuales de nuestra sociedad global y tiende, en definitiva, a educar para la dignidad humana y para una vida humana digna. En consecuencia, se trata asimismo de educar en los recursos y contenidos morales como valores, normas, virtudes y actitudes básicas; de cultivar la justicia, de disfrutar del placer y del bienestar; de saber y de esforzarse por lograr las metas y proyectos propuestos, de transformar moralmente la forma de pensar y de valorar y de invertir la escala de valores, de desarrollar y cultivar las aptitudes y capacidades cognitivas, emocionales y motivacionales, etc. Las teorías psicológicas y pedagógicas han de pensar cómo llevarlo a cabo.

Recibido: 11/09/2008

Aceptado: 17/11/2008 